\title{
Narratives of Sick Leave, Return to Work and Job Mobility for People with Common Mental Disorders in Sweden
}

Christian Ståhl and Elinor Edvardsson Stiwne

The self-archived postprint version of this journal article is available at Linköping University Institutional Repository (DiVA):

http:// urn.kb.se/ resolve?urn=urn:nbn:se:liu:diva- 105560

N.B.: When citing this work, cite the original publication.

The original publication is available at www.springerlink.com:

Ståhl, C., Edvardsson Stiwne, E., (2014), Narratives of Sick Leave, Return to Work and J ob Mobility for People with Common Mental Disorders in Sweden, J ournal of occupational rehabilitation, 24(3), 543-554. https:/ / doi.org/ 10.1007/ s10926-0139480-7

Original publication available at:

https:/ / doi.org/ 10.1007/ s10926-013-9480-7

Copyright: Springer Verlag (Germany)

http:// www.springerlink.com/ ?MUD=MP 


\title{
Narratives of sick leave, return to work and job mobility for people with common mental disorders in Sweden
}

\author{
Christian Ståhl ${ }^{1}$, Elinor Edvardsson Stiwne ${ }^{2}$
}

\author{
${ }^{1}$ National Centre of Work and Rehabilitation, Department of Medical and Health Sciences, Linköping \\ University, 58183 Linköping, Sweden. christian.stahl@liu.se \\ ${ }^{2}$ Education and Adult Learning, Department of Behavioural Sciences and Learning, Linköping University, 581 \\ 83 Linköping, Sweden. elinor.edvardsson.stiwne@liu.se
}

Corresponding author:

Christian Ståhl

E-mail: christian.stahl@liu.se

Tel: +46 (0)10-1031457

National Centre of Work and Rehabilitation, Department of Medical and Health Sciences, Linköping University, 58183 Linköping, Sweden.

\begin{abstract}
Purpose: The aim of this study was to analyze how different types of sick leave narratives were related to RTW, job mobility or continued sick leave for people sick-listed with common mental disorders. Special attention was paid to how the respondents described their contacts with employers and rehabilitation professionals.
\end{abstract}

Methods: Eight persons sick-listed with CMDs were interviewed at two occasions (2005-2006 and 2008-2009) about their self-perceptions, their sick leave, and their contacts with their employers and rehabilitation professionals, first during their first months as sick-listed, and a follow-up after approximately four years.

Results: Two types of narratives were identified: restitutive (with focus on recovery and RTW), and contingent (focusing on managing the present). A common theme was that mental problems were not recognized and talked about in the same way as physical problems. This had consequences for peoples' acceptance of their diagnoses and for the RTW processes.

Conclusions: In restitutive narratives, RTW was essential for returning to life as it was, where support from managers and colleagues facilitated a successful return. In contingent narratives, the experience of sick leave was part of a broader story of change where work relations were of less importance. A narrative understanding of rehabilitation involves sensitivity toward the stories people are caught up in, and what role professionals may play in them. Promotion of job mobility may be difficult to accept for persons with restitutive narratives, while persons caught up in contingent narratives may be more open - and benefit more - from such solutions.

Keywords: Sweden; sickness absence; return to work; job mobility; mental health; identity 


\section{Introduction}

Common mental disorders (CMDs) include depression, anxiety, panic, obsessive-compulsive and stress disorders. CMDs, and anxiety in particular, have been identified as a risk factor for future sick leave [1], and the recurrence is high [2]. In Sweden, mental health problems is one of the most common causes for sick leave, especially for women [3], and may have negative individual, social and economic consequences. Reports from the Social Insurance Agency note that sickness absence due to mental health problems is more common in careoriented occupations, such as psychologists or social workers [4].

Studies suggest that return to work (RTW) for people with CMDs is determined by a combination of work- and health-related factors [5], and that RTW interventions need to target both [6], with special attention to coordination between the social and rehabilitation systems [7]. There are several stakeholders involved in RTW processes (most commonly workers, employers, insurance representatives and healthcare professionals), all representing different perspectives [8]. In relation to CMDs, it has been suggested that supervisors and physicians focus on at-work functioning and sustainability, while workers tend to include more aspects such as work-home-balance, mental functioning and job satisfaction [9].

Motivation to RTW generally diminishes as time passes: Millward et al [10] described how people with moderate or severe depression tended to develop an incapacitated identity over time. Further, daily life is affected through increased emotional sensitivity, and the ability to cope with daily routines and social obligations diminishes [11]. Sickness benefits are often dependent on a medical diagnosis; however, being diagnosed with CMD is for many people associated with feelings of shame [12, 13], which implies that some may find it difficult to accept such diagnoses.

In order to better understand the conditions for RTW for people sick-listed for CMDs, it is relevant to study how peoples' self-perceptions are influenced by and influence the contacts they have with their employers, healthcare or other professionals in the RTW process. This study focuses on how people sick-listed with CMDs narrate their sick leave experiences, where the aim was to analyze how different types of narratives were related to RTW, job mobility or continued sick leave. Further, special attention was paid to how the respondents described their contacts with employers and rehabilitation professionals. A theoretical framework based on narrative research on illness and unemployment was used to analyze the narratives. 


\section{Narratives of illness and job loss: a theoretical framework}

There are several conceptualizations of how people develop their identities after dramatic life events. Here, the concepts of identity and narrative are closely interwoven, where it is assumed that peoples' identities are constructed through social processes in which their narratives (or stories, the concepts are used synonymous) of themselves contribute to their perceptions of self-continuity [14]. A narrative thus have a temporal element: it is identity in transition.

In his analyses of illness, Frank [15] notes how the development of medical technology imply that most illnesses today are possible to treat (it has also been noted how an increasing amount of conditions has been medicalized through diagnostic manuals, cf. [16]), with the consequence that many live their lives in long processes of recovery. These people live in a "remission society", where they construct their life stories in relation to how their illness influences their identity. From this background, Frank has identified three different types of narratives: restitution, chaos, and quest.

Restitution stories attempt to outdistance mortality by rendering illness transitory. Chaos stories are sucked into the undertow of illness and the disasters that attend it. Quest stories meet suffering head on; they accept illness and seek to use it. [...] The quest is defined by the ill person's belief that something is to be gained through the experience. [15, p. 115]

In this conceptualization, control and chaos are understood as opposite ends of a continuum. Restitution stories presuppose that while the ill person may experience lack of control, others (e.g., healthcare professionals or relatives) are able to take care of the person and his or her problems. Chaos narratives, on the other hand, presuppose a lack of control not only for the ill person, but also from those taking care of him or her. In a RTW context, the responsibility for the process - and thus the control over the situation - may be spread out over several actors: insurance institutions that administer benefits, healthcare professionals that certify the diagnosis, and employers that may or may not adjust the workplace to accommodate the person. A sick-listed person’s lack of control thus needs to be supplemented with control provided by several other actors, which may make restitution complicated.

In a further elaboration, Frank noted how perceiving illness as drama may introduce meaning and value into the narratives; he points out how a drama may actually be enjoyed if the person plays the part well, even when this implies adopting a vulnerable position [17]. Giving up control may even be seen as a relief, and involve a 
longed-for liberation from coping with problems. Perceiving illness as drama is particularly obvious in quest narratives, which tend to emphasize conflict. In such narratives, the ill person will perceive themselves as the hero in their story, where others may be perceived as trying to make their lives difficult. In a sick-leave context, such roles may be attributed to the insurance system, to healthcare, or to the employer.

Ezzy [18] distinguishes between linear and polyphonic illness narratives. Linear narratives colonize the future and may be restitutive (anticipating recovery) or chaotic (anticipating a life failing to meet the ideal state). Polyphonic narratives, in contrast, are oriented toward the present, where the future is seen as unpredictable; such narratives also tend to involve spiritual or religious experiences. Ezzy relates these narratives to Frank’s concepts, where restitution and chaos narratives are considered linear, and quest narratives are considered polyphonic [18]. These are also related to Davies’s distinction between three temporal orientations: "living in the future”, "living in the empty present”, and "living with a philosophy of the present” [19].

Quest narratives have their equivalent in studies of unemployment, where Ezzy [20, 21] distinguishes between heroic and tragic narratives. While the former tend to emphasize individual agency and downplay the influence of social structures, the latter tend to do the opposite: people perceiving themselves as victims of events beyond their control (cf. illness as drama). Narratives are shaped in complex processes involving individual and social factors, and "the extent to which a person is able to exercise choice, or 'agency' is in part a product of social location” [20, p. 131]. The effects of job loss are generally stronger the greater the commitment to the previous job: when losing one's job, the person needs to construct a new narrative that refigures the past, while simultaneously prefiguring the future. Job loss may also be seen as a status passage, where losing one’s job also may imply losing essential parts of one's identity and the foundations of one's social position. Related to RTW, it is likely that a successful return would be attributed to both individual agency and supportive structures, while a failed RTW would more likely be attributed to external factors. It is also reasonable that work identity matters for how the person will value RTW. In RTW research, it has been suggested that attention should be given to the person's readiness for change, which may affect what rehabilitation interventions that are appropriate [22]. It is hypothesized that workers may be in different phases in which RTW seems more or less relevant or realistic, which is likely to be connected to both the person's medical condition and the work situation.

Frank [23] notes how dialogue between physicians and patients is generally more equal in cases where the patient occupies a similar social position as the physician; in conflicts between patients and healthcare professionals, the moral horizon of the two may differ. Due to the vulnerability of the patient, Frank argues, 
healthcare professionals may be considered having a greater responsibility for understanding the patient's story than vice versa. In RTW processes, we also need to consider contacts with social insurance officials and employers, where the conditions for equal dialogue may be different than in healthcare, due to these actors' influence over the person's financial situation. Here, it is also relevant to refer to the person's experience of justice and recognition in the rehabilitation process, where it has been noted how perceptions of injustice, mistrust or stigmatization negatively affects the conditions for RTW [24-26].

In this study, the perspectives outlined above will be related to the sick-listed persons' experiences and how these were told to the researchers. In our analysis, focus will be on how the respondents construct their narratives related to perceptions about the future in terms of RTW or job mobility, and their need to manage their work disability.

\section{Methods}

The eight respondents in this study were interviewed on two occasions, with three to four years interval. The selection of respondents was based on two criteria: being diagnosed with common mental disorders, and being on sick leave. Their contact information was supplied by Swedish primary healthcare centers. Seven of the respondents were women, and their ages spanned between 30 and 57. At the first interview, the respondents' level of sick leave varied from 25 to 100\%, and sick leave length between 1 and 18 months (Table 1).

(Table 1 about here)

The first interviews were carried out in 2005 and 2006 in the interviewees' homes and focused on the period when they were diagnosed and sick-listed, their experiences and explanations of why this happened, how the RTW process had worked so far (including support from their managers and co-workers), contacts with rehabilitation professionals, and thoughts about the future. The second interviews were carried out in 2008 and 2009, following up what had happened since the first interview. All interviews were transcribed verbatim.

The two sets of interviews were carried out by different interviewers, and the analysis was made in 2013 by two other researchers who had not met the respondents. The analysis was therefore carried out as a qualitative text analysis based on the interview transcripts. The material was interpreted with support from concepts derived 
from the theoretical framework, and analyzed through an iterative process [27] where the developing categorization was influenced by the empirical findings as well as previous conceptualizations.

The study was approved by the regional ethics board in Linköping, Sweden. Written informed consent was collected from the participants. All names of the respondents have been changed in this article.

\section{Results}

The eight individual narratives could be organized into two broad categories: restitutive and contingent narratives. A summary of the respondents’ narratives is presented in Table 2.

(Table 2 about here)

\section{Restitutive narratives: recovery and return to work}

The most common narrative among the respondents was the linear restitution story, which had in common the goal to return to a previous state of normality. The illness and the sick leave were generally perceived as a temporary disruption from the respondents’ ordinary life, from which they were to recover. For Lisa and Maria, RTW was relatively straight-forward, while Emma, Lena and Alexandra described processes that were negatively influenced either by life events or by poor support from managers or colleagues.

\section{Lisa: An unproblematic return}

At the first interview, Lisa described having problems accepting her diagnosis, where she preferred to locate the cause for her illness in a rapid weight loss (35 kg in a year). She could not understand why she was sad and tired, which made her conclude that depression was not the right diagnosis: “depression, then you'd know why you're sad, I think.” She had problems recognizing herself, and why she was angry, sad and "strange”.

At the second interview she seemed to have accepted her diagnosis, although she still located the cause of the illness to her body rather than her mind. She had at this point fully returned after a short period with part-time sick leave. While still being ambivalent toward her condition, she expressed a new understanding for mental health problems: 
"I have a completely different understanding now of those who have it [depression] ". (Second interview)

In Lisa’s story, RTW was described as an uncomplicated process, since both she and her employer wanted her to return. She described her future as "great”, and added that hopefully, she would "never get this sick again”. Lisa perceived both her colleagues and her manager as very understanding of her situation. However, she experienced being pushed into returning faster than expected, but seemed to have managed this partly due to worries about losing her job. Although feeling supported, she noted how the manager did not follow up the RTW: once back it was business as usual.

In this case, the social relations at work helped Lisa to manage RTW despite relatively high work demands. She described how it had taken her a couple of years to get well again, and that she never told managers and colleagues about her problems with managing the work. It remained a private matter to her, to find ways to cope with the work load, despite her continuing illness.

\section{Maria: Returning through a supportive alliance}

At the first interview, Maria preferred to speak of herself as "finished as a human being" rather than using the word “depressed”. At first, she explained the causes of her problems as non-work-related psychic illness. Her problem was that she looked healthy, but she had lost all her energy. She was troubled by the physical invisibility of her problems which made her feel guilty for receiving sickness benefits.

Maria’s RTW was facilitated by the support from her physician who claimed to take the responsibility if RTW would not work:

He [the physician] said, 'you can always try, and if it doesn't work it's not your fault, but mine'. (First interview)

Here, the physician became a partner in the RTW process through sharing the responsibility, which in combination with good support from her manager helped her to return to work. The manager talked to Maria’s colleagues about her condition to make sure they let her do things in her own pace, and the manager had continuous meetings with Maria to make sure that everything worked out well. She was free to return gradually without being forced by the Social Insurance Agency or the employer. 
Her RTW was delayed by the sudden death of her husband, but at the second interview she was back at work on full time. She described how retaining her identity at work was important for her recovery, and at the second interview she described her current state as relatively good.

\section{Emma: Managing guilt and shame}

At first, Emma could accept having a stress reaction, but not that she was diagnosed with a panic disorder. While on sick leave, she had feelings of guilt and shame for being home alone while having her children in daycare and for the employer's costs for her sick leave. She had no previous experience of illness and could only in retrospect see indications of what was coming. Her explanations for this were a combination of work demands and her private life.

She also had a feeling that other people questioned her condition due to the invisibility of her problems, and she noted that it was her responsibility to make her problems visible in order to make her colleagues and managers to understand her reactions. Emma described that although her manager was supportive in the RTW process, the illness was quickly forgotten since the problems were not visible: she looked "functional", and therefore the manager did not follow up the RTW:

Once you're back and seem ok again, the management quickly forgets. That's the way it is, I've seen it twice now. (Second interview)

Emma described a tough work situation, with limited managerial support and high work peaks; her colleagues were however supportive, since several of them had similar experiences. The employer also seemed prone to explain the cause of Emma's illness with reference to her personal life rather than the work, but the work group’s shared experience of a tough work situation helped her to cope with the lack of support from the management.

She had found it difficult to let go of her work while being on sick leave, fearing that she would be replaced by a temporary worker. The first attempt of returning to work was relatively fast which caused a relapse. After that, the next attempt was made more gradually while her employer adjusted her work tasks. 


\section{Lena: Varying support}

Lena was working in military kitchen, with some flexibility in her working hours. She described her work as physically tough and did not express any strong identification with it. After her daughter was diagnosed with a panic disorder and eventually put out of school, Lena had a stress reaction and was put on full time sick leave, partly to nurse her daughter. The cause of her sick leave was clearly not work-related, but very stressful for the whole family.

Lena's plan for the future at the first interview was to return to work at full time, in order to "manage more and feel like my old self”. At the first interview, she had returned to work at 50\%. She described how she did not trust her manager, who tried to force a faster RTW. At the second interview she was back on full time and described the RTW process as supported by her colleagues and a new more supportive manager who let her decide on the pace for her return:

It's at least an understanding manager [...]. The other manager would sigh and say 'now again, you're away all the time, think about your work mates'. I'd hear that all the time. (Second interview)

At the second interview, she seemed relatively content with her present situation since her daughter was older and taking care of herself, and because RTW seemed to have worked out well and she felt supported in being back.

\section{Alexandra: Keeping your face up}

Alexandra described how she managed to function well in her work as a pre-school teacher, while being less functional at home. She described how her partner (and her dog) sensed how her breakdown was coming while neither she nor her work colleagues did. This, she meant, illustrated how she kept her face up at work while breaking down underneath the surface. As a result, her experience was that she was not believed in or supported by her manager or her colleagues when she was sick-listed. Her strong work commitment was here clearly related to her feelings of not being believed or supported:

As my manager said: 'You're so happy, and you bring in so many good ideas.' Yes, I said, that's my work-, that's my costume that I put on. (Second interview) 
Expressing a strong work identity served to hide and downplay her mental health problems, which in turn complicated her RTW. At the first interview, Alexandra saw her future as back at work, but since she was not supported by her workplace contacts she did not manage to return. Ultimately, this forced her to change workplace, and she was able to find a new job within the same profession that could better accommodate her needs. At the second interview she was working again.

Alexandra described how she had had difficulties in coming to terms with who she was after her illness, and that she had considered a change of career. She decided however to stay within her profession, where one reason for this was the difficulties involved with learning a new job after having been depressed.

At the time of Alexandra's sick leave, there was also a media debate about cheating in the sickness insurance system that made her feel even more questioned, being a part of a larger "percentage” of people feigning illness: she described considerable mental stress related to her dealings with the Social Insurance Agency.

\section{Contingent narratives: managing the present}

Three of the respondents (Anna, John and Suzanne) told stories that to a higher degree embraced contingency and change, as such being less linear or based on a specific anticipated future. Although both Anna and John returned to work (permanently or temporarily) this was not as clearly related to retaining their narratives as in the other cases.

\section{Anna: Making do with what is left}

When describing her situation, Anna was very reticent about the cause for her sick leave. She described it as a family crisis which led to a large life disruption and a complete loss of structure, where she broke her relationship with her husband and lost her house. The situation was described as caused by events beyond her control, with consequences for her self-image as well as her social relations. Anna told a story characterized by chaos, where she had troubles managing everyday tasks and needing to adapt to a future with many limitations. She kept returning to the notion of a changed self, from having been strong to becoming weak. In the first interview her life was very chaotic and she perceived how her changing identity seemed to make others afraid of her, and insecure about how to handle her and her situation. She was at the second interview both concerned with 
the future and the present: she worried that she would not manage financially after retirement unless she kept working, while she also struggled to manage contingency and coping with her current problems.

Although the primary reason for returning to work seemed to be her financial worries, she also described how RTW was a part of an urge to sustain something of her previous identity while her personal life collapsed. However, since she kept the causes of her problems as a secret to her manager and her colleagues, her work relations and the RTW process became difficult:

The employer doesn't know what has happened, and it bothers them. Especially in the beginning there was much fuss about everything being better if I told them. [...] They were very frustrated about not knowing. Well, they don't and they never will. (First interview)

While recovering from her depression she was also diagnosed with cancer, which further delayed RTW. In the second interview she was back at work on full time although experiencing problems with the work pace. She described herself as actively promoting her own RTW despite her situation, with little support from managers and colleagues. Her job as an interviewer involved much solitary work and traveling to visit interviewees, where the work hours were unpredictable and the possibilities for adjustments were limited. She described how she had thought about changing jobs due to these conditions, but since she did not have much education and still could enjoy the work she had decided to stay with it.

Anna's narrative was clearly tainted by tragedy and by her feelings of being an innocent victim of external events. In so being, the narrative had strong chaotic elements, where she resigned from her previous anticipated future and slowly began to accept an impaired version of herself. Her future was oriented mostly towards coping and picking up the pieces left after her illness. Hence, the overarching themes of her narrative were resignation and embracing contingency, where the future was clouded by the uncertainties of recovery that was perceived as a wished-for rather than a realistic goal. Returning to work was in this process primarily a way for her to make a living while she struggled with managing the present.

\section{John: The survival artist}

In John’s story, he ascribed the cause for his illness to a combination of a personal tendency for overcommitment, a non-supportive employer, and a demanding work situation (social work with children in a school setting). He claimed that the illness was primarily work related, but that the consequences were personal. He had 
experiences from two different employers where one was perceived as supportive (for instance by offering access to occupational health services), while the current one was described as notoriously bad.

I'd say I have a very bad employer. They don't have any collective agreements with the unions, and if it doesn't suit you, then you'll just... [laughs]. It's great as long as you're performing well, but then... There's more people there that's been on sick leave. [...] My employer here now, he follows the work legislation precisely, but he uses it as he pleases. (First interview)

John was fired as a consequence of becoming sick-listed, and his first employer took no responsibility for him. Although he told quite a demeaning story about his employer, he refused to claim any bitterness. For a short period of time he also had returned to the job, despite that he had been fired, since he needed the money. This surprised his colleagues who seemed to have expected him to not accept the offer.

I didn't think I needed to swallow any pride to go back, but they [colleagues] thought they [the employer] had treated me really bad, the way they fired me. (Second interview)

While lacking support from his employer, John described the Social Insurance Agency and his healthcare contacts as supportive. In the first interview, he thought that he would be working again in a year, probably in a temporary job. He described a diverse work history which made him open to different jobs in the future: his work identity was based on being flexible, rather than invested in a particular profession.

At the time of the second interview, John no longer worked in the school sector, and claimed that the reason was that he wanted a job that did not involve working with people. Instead, he made a living through different temporary jobs, mostly in construction. He described how sick leave had given him a different outlook on life and work commitment: since work had brought him down, he would not again let poor working conditions lead him to illness. Still, he expressed a rather masculine self-image, describing himself as a Viking that ought to cope with harsh working conditions. He seemed to enjoy doing more physical labor, and was content with keeping temporary jobs and having different sources of income.

John's story was characterized by accepting and living with contingency, and much of his reasoning at the second interview revolved around being in and embracing the present, and valuing health over money. His future plans seemed vague, which did not seem to trouble him. John’s narrative was highly polyphonic - it evolved without being tied to any specific anticipated future, seizing opportunities as they presented themselves. This was reinforced by his scattered work identity: job mobility was not a big deal for him, since his entire work 
history was made up of such changes. He presented himself as a survival artist that, in spite of conditions being to his disadvantage, managed to find his way through whatever troubles that faced him. In such, his narrative was a reflection of constant change.

\section{Suzanne: The heroic victim}

The clearest quest narrative among the interviewees was Suzanne’s. She told a story in which her managers and colleagues were pictured as incompetent, mean, disrespectful, jealous, and having personal problems. Her presentation of herself was, in contrast, that of an over-competent, artistic person with strong ties to a successful family (her husband being retired from an academic profession, her children holding well-qualified jobs, or being very musically talented). She told that she had been involved in a long conflict with her employer, where her manager had repeatedly accused her for various incidents and finally decided to fire her. She had engaged a union representative in the conflict and managed to win, forcing the employer to withdraw the suspension and offer her compensation.

The manager handed me a paper [...] and there were a lot of remarks about me, all kinds of rubbish, and it's so silly all of it, hadn't it been so dumb. [...] When [an old friend] heard about this, she looked at me and said, have you ever thought they may be jealous of you? And that's the kind of thoughts you get. (First interview)

She perceived herself being abused in all her contacts with her employer (and several of her colleagues), and at the time of the first interview she had been sick listed on full time for five months. She described the cause as a combination of medical problems, the conflict at work and her working conditions. She also told how she had had similar conflicts with previous employers which she claimed to have chosen to leave. At the second interview the situation seemed mostly unchanged, and she was still sick-listed on full time. Suzanne did not consider returning to the previous employer as an option, and she expressed that she probably would want to have another job later on; however, the future was obscured by her (and her husband's) medical problems.

Suzanne’s story was a clear quest narrative in which the heroes and enemies were obvious; most people, including herself and her family, were described as either angels or demons. Although she claimed she wanted to find another job she seemed quite content with being a heroic victim of unfair treatment. RTW was in this case considered as not possible, where it was clear that the employer did not want her back. Suzanne's perception of 
the situation however seemed to be that she had won the conflict with her employer and now could choose whether she wanted to return or not. She described that her RTW was prevented through a combination of medical problems and the prospect of returning to a workplace where she was not welcome: "I'll never go back to that workplace, never!”

\section{Discussion}

When narrating sick leave, a complex array of factors come into play. The possibilities for accommodation and support from employers, colleagues, healthcare professionals and insurance officials are influenced by the diagnosis, personal conditions (e.g., physical and mental capabilities, motivation and work identity), structural conditions (e.g., sickness insurance regulations, work conditions), as well as the quality of the interactions. This complex interplay of factors will influence whether a person will remain on sick leave, return to work, or change to a new job. With the right level of support, coupled with individual motivation and capability, people may retain their narratives and return to their jobs and their old selves. Without, they may need to adapt to a contingent narrative, which may take different forms. The restitution narrative is strong in sick-leave narratives, illustrated here by the common focus on returning to the previous job, or to a similar one. In contingent stories, however, changes in peoples' life situations force them to break with their narratives. The results show three rather different reactions to such a narrative break: resignation (Anna), opportunity (John), or quest (Suzanne). Figure 1 illustrates how these relations appeared in the material.

(Figure 1 about here)

\section{Narratives, RTW and job mobility}

People invest time and effort into forming a work identity, which implies that RTW is regularly the first option after sick leave. While RTW and restitution narratives are often related, the results show how it is not a one-toone relationship. RTW may be a way to retain a narrative, as for Lisa and Maria, where RTW was a primary goal both for them and their employers and where they felt supported enough to manage this process. Being back at work was here an essential part of their recovery. For Emma and Lena, RTW was important but not essential, 
since the job was either perceived as a part of the cause of the sick leave or because they did not identify strongly with their work.

In contingent narratives, RTW may be an economic necessity when life changes, as for Anna, who returned to her job while living much in the present (cf. "living in the empty present”, [19]), or for John, who returned for financial reasons while later leaving the job. RTW in contingent narratives may thus be a consequence of a lack of alternatives. Likewise, contingent narratives and job mobility are not always related: while Anna returned, Alexandra changed jobs in order to retain her narrative, where the new job (in the same profession) better suited her medical condition. Her focus was on personal continuity expressed through her work identity, thereby expressing a linear narrative, albeit with recognition of contingency through her openness toward changing workplace.

The experience and expression of support from different actors vary. For people with a restitution narrative, support from managers and colleagues seems essential for their ability to return to work, and for returning to their "old selves". For people with contingent narratives, the experience of sick leave is subordinated to a broader story of change: into overcoming challenges or accepting uncertainty. While support from managers and colleagues may be of importance here as well, these people may be less dependent on their previous contacts. This relationship is likely two-sided: lack of support could imply that the narrative is re-defined into a quest or into a changed work identity. Hence, the relationship between narratives and RTW is not causal: narratives change, and are influenced by external events.

A narrative is deeply embedded in individuals' social positions, where the actual possibility for job mobility varies depending on age, gender, education and work experience. For John with his diverse work history, changing jobs was not considered a big leap. His highly contingent narrative may be contrasted with Maria and Anna, who despite many obstacles returned to their jobs, either because they had a long-term investment in their work identities, or lack of alternatives due to a low educational level. Alexandra, on the other hand, had a strong work identity but changed into a similar job where the new workplace could better accommodate her; she thus illustrate how change may be necessary in order to continue a previous narrative.

The sample in this study was primarily made up of women working in jobs involving care of people (elderly care, social work, nursery school, etc.). Such occupations generally have an over-representation of women, and such occupations are over-represented in terms of sick leave caused by CMDs. It may be argued that the health problems related to such jobs are related to a conflict between meeting a high work load and giving the people 
one cares for the appropriate time and consideration. John's argument that it was a relief to change into a job that did not involve working with people may be seen as symptomatic for such a conflict. The over-representation of women among those sick-listed with CMDs may be related to the specific work conditions in "female" occupations. The material suggests that RTW in such jobs require adequate support from colleagues and managers, where several of the respondents notes how such support facilitated their return, despite a high work load. John's job mobility can in this respect also be seen as an opportunity that, at least partly, was connected to his gender, where he moved from a traditionally female occupation to a more "masculine” job; it could be argued that women have fewer possibilities finding such alternative occupations. As such, if sickness absence due to CMDs is gendered, it is because the labor market is gendered.

Shifting from RTW to job mobility is often a feature in rehabilitation schemes that is introduced either after a set time limit, or when RTW is deemed not to be possible. A narrative understanding of such processes is sensitive to whether a shift of focus is in line with the individuals' perceptions of themselves, and the possibilities one perceives to have of finding another job. A person who narrates his or her life story through a restitution lens may find it difficult to accept a change of career as a solution to the problem, or might even be offended by such a suggestion. Promoting job mobility for people on sick leave presupposes that the individual is ready to adopt a contingent or change-oriented narrative which may be difficult if much effort has been invested in their present occupation, or if they have limited education. Changing jobs may be a more dramatic change for those with a strong work identity, but where medical or other factors make RTW impossible. It may also involve a status passage, where the person has to accept a job in a lower position, with lower pay [cf. 21].

\section{Invisibility and disclosure}

Receiving a mental diagnosis involved feelings of chaos, where the experiences of not recognizing oneself and losing control over one's reactions were common. A recurrent theme in the interviews was the experience of mental health problems as “invisibly”, which was experienced both in the respondents' own understanding of their situation and in their contacts with others

Millward et al [10] noted how several participants in their study felt guilty when engaging in enjoyable activities, which was seen as incongruent with their "ill” condition. This self-inhibiting attitude was visible also in this material, where respondents felt guilt when being out of their homes "looking healthy” while simultaneously receiving sickness benefits. The feeling of being a societal burden was recurrent. 
Their diagnoses, as well as the perceived invisibility of their problems, had consequences for the respondents' relations with managers, colleagues and others: since they seemed functional, the employer was uncertain of how to deal with their disabilities. In a review of the literature about disclosure of mental illness in the workplace, it was concluded that there are several reasons for why people choose not to disclose their conditions. This included expectations or experiences of discrimination, feeling that the condition is a private matter, or feelings that others do not want to know about it; reasons for disclosing one's illness, on the other hand, was connected to being a role-model for others, to have work adjusted, being honest, receiving support, and because concealing illness is stressful [28]. The review also noted that feelings of emotional support were connected to disclosure, which was apparent also in the present study: most clearly in Anna's case, where her refusal to disclose her chaotic life situation caused her to become estranged from her colleagues and managers, which seemed to have obstructed her RTW. While disclosure may be daunting for the ill person, it has also been emphasized that it requires competence on the side of the employer in dealing with the problems and managing RTW [29]. Lemieux et al [30] have noted that there is often a workplace norm of not asking questions when somebody has mental problems, where the lack of information may make RTW interventions or adaptations more difficult. It has also been noted that RTW policies often fail to incorporate the back-at-work phase [31]. Frank [17] emphasizes the importance of naming and articulating problems, and that fears “multiply in silence, but when people engage in dialogue about fears, they construct imaginations of themselves that make their fears literally livable.” [17, p. 388]. The responsibility for articulating problems is often placed on the sick-listed person, while managers and colleagues quickly forgets and expect the person to engage in business as usual (as noted by Emma).

Even in a successful RTW story, as Lisa’s, the invisibility of her problems still caused trouble, where she did not disclose her diminished capabilities but chose to cope with them in silence. For her, as for Emma, fear of losing the job was mentioned as an important factor for returning, which made her accept a faster return than she had hoped for, and to accept business as usual when back at work.

\section{Choosing interventions}

Frank [15] describes how a narrative ethic (for healthcare) involves a holistic perspective on ill persons, rather than reducing them to patients; he emphasizes the need to acknowledge how different voices narrate the same situation, thereby producing different stories. This observation may be generalized into the different stakeholders 
in the RTW process, where the need for coherence and coordination has been pointed out [7]. In Frank's perspective, this implies a dialogue in which the illness can be placed into a coherent story [17]. A dialogical relationship was obvious in Maria's case, where the physician managed to support her in retaining her narrative. Suzanne's story, in contrast, showed how the different actors could not find any common ground in which to resolve their conflicts: as a consequence, she did not return to the workplace. Suzanne's story, in contrast, illustrates a case where the actors did not share the same understanding of a situation (a "how can they act like that” story, as described by Frank [23]), where it would be reasonable to assume that Suzanne and her employer had made each other into characters in their respective stories, framed through different moral horizons.

Millward et al note how healthcare professionals tend to engage in "reinforcing the 'sick role' and in so doing providing a continued justification for an 'off-work' identity” [10, p. 565]; they also propose a "narrative therapy” in which illness is reframed into something that can be overcome, to form realistic recovery goals. Although such a therapy may not be relevant in all cases or for all stakeholders, it could inspire an approach to the ill person where the personal narrative is taken into account when proposing rehabilitation measures.

It is also relevant here to note, as Ekberg et al [32], how the type of intervention that is proposed needs to be tailored to the individual situation, where it in some cases would be reasonable to promote workplace interventions (for instance, where it is unlikely that the person will manage to find another job), while in others, job mobility may be a better option. It has been suggested that RTW interventions need to pay attention to the person's readiness for change [22]. The present study suggests how the readiness for change may be differentiated in terms of different types of change, where RTW and job mobility are connected not only to peoples' social positions, but also to which type of narratives they have developed. In this study, contingent narratives appear to be more open to the more dramatic change that job mobility implies, while restitution narratives seem more oriented towards RTW.

\section{Methodological considerations}

The ambition of this study was to generalize results to narrative theory rather than to a broad population, in which the longitudinal data helped to strengthen the analysis in terms of trustworthiness [33]. Since the analysis was not carried out by the persons who made the interviews, the study is to be considered as a text analysis, 
which however is not thought to influence the possibilities for making conclusions from the material. The sample is however limited to people with CMDs, and conclusions may not be transferrable to other conditions.

\section{Conclusions}

The concepts developed in narrative theories of illness and unemployment have in this study been proven to be useful for analyzing sick leave and RTW. We propose that restitution and contingency may be used as overarching categories into which sick-listed persons' narratives may be organized, based on how people imagine their future. In restitutive narratives, RTW is an essential part of returning to their life as it was, where support from managers and colleagues seems central for a successful return. Contingent narratives are more heterogeneous: people may or may not return to work, and when they do, it is out of necessity in order to manage the present, rather than to retain their disrupted narrative. The experience of sick leave is in these narratives part of a broader story of change - in this material characterized by resignation, opportunity or quest - in which work relations may be of less importance.

Consequently, a narrative understanding of occupational or vocational rehabilitation for people on sick leave involves acknowledgment of and sensitivity toward what story the person is caught up in, and what role the professional may play in that story. A coherent restitution narrative in which the actors define the situation in similar terms seems to facilitate RTW. As many rehabilitation schemes involve promotion of job mobility, it should be noted how a person narrating his or her story through a restitution lens may find this difficult to accept, while persons caught up in contingent narratives may be more open - and benefit more - from such solutions.

\section{Acknowledgements}

The authors wish to acknowledge Lena Strindlund and Ann-Christine Larsson who carried out the interviews, and Kerstin Ekberg, who contributed to the study design and commented on the manuscript.

\section{References}

1. Knudsen AK, Harvey SB, Mykletun A, Øverland S. Common mental disorders and longterm sickness absence in a general working population. The Hordaland Health Study. Acta Psychiatrica Scandinavica. 2013;127(4):287-97. 
2. Koopmans PC, Bültmann U, Roelen CAM, Hoedeman R, Van Der Klink JJL, Groothoff JW. Recurrence of sickness absence due to common mental disorders. International Archives of Occupational and Environmental Health. 2011;84(2):193-201.

3. Försäkringskassan. Långtidssjukskrivna (Long time sickness absentees). Stockholm: Försäkringskassan (Social Insurance Agency), 2010, 2010:16.

4. Försäkringskassan. Sjukskrivningsdiagnoser i olika yrken (Sick-listing diagnoses in different occupations). Stockholm: Försäkringskassan (Social Insurance Agency), 2011, 2011:17.

5. Nieuwenhuijsen K, Noordik E, van Dijk FJH, van der Klink JJ. Return to Work Perceptions and Actual Return to Work in Workers with Common Mental Disorders. Journal of Occupational Rehabilitation. 2012:1-10.

6. Pomaki G, Franche RL, Murray E, Khushrushahi N, Lampinen TM. Workplace-based work disability prevention interventions for workers with common mental health conditions: A review of the literature. Journal of Occupational Rehabilitation. 2012;22(2):182-95.

7. Andersen MF, Nielsen KM, Brinkmann S. Meta-synthesis of qualitative research on return to work among employees with common mental disorders. Scandinavian Journal of Work, Environment \& Health. 2012;38(2):93-104.

8. Franche R-L, Baril R, Shaw W, Nicholas M, Loisel P. Workplace-Based Return-to-Work Interventions: Optimizing the Role of Stakeholders in Implementation and Research. Journal of Occupational Rehabilitation. 2005;15(4):525-42.

9. Hees HL, Nieuwenhuijsen K, Koeter MWJ, Bültmann U, Schene AH. Towards a new definition of return-to-work outcomes in common mental disorders from a multistakeholder perspective. PLoS ONE. 2012;7(6).

10. Millward LJ, Lutte A, Purvis RG. Depression and the perpetuation of an incapacitated identity as an inhibitor of return to work. Journal of Psychiatric and Mental Health Nursing. 2005;12(5):565-73.

11. Sobocki P. Health economics of depression. Stockholm: Karolinska institutet; 2006.

12. Retzinger SM. Violent emotions: Shame and rage in martial quarrels. London: Sage; 1991.

13. Scheff TJ. Shame and community: Social components in depression. Psychiatry. 2001;64(3):212-24.

14. Ezzy D. Theorizing narrative identity: Symbolic interactionism and hermeneutics. Sociological Quarterly. 1998;39(2):239-52.

15. Frank AW. The Wounded Storyteller: Body, Illness, and Ethics. Chicago: The University of Chicago Press; 1995.

16. Kawa S, Giordano J. A brief historicity of the Diagnostic and Statistical Manual of Mental Disorders: Issues and implications for the future of psychiatric canon and practice. Philosophy, Ethics, and Humanities in Medicine. 2012;7(1).

17. Frank AW. Five dramas of illness. Perspectives in Biology and Medicine 2007;50(3):37994.

18. Ezzy D. Illness narratives: time, hope and HIV. Social Science \& Medicine. 2000;50(5):605-17.

19. Davies M. Shattered assumptions: time and the experience of long-term HIV positivity. Social Science \& Medicine. 1997;44(5):561-71.

20. Ezzy D. Fate and agency in job loss narratives. Qualitative Sociology. 2000;23(1):121-34.

21. Ezzy D. Narrating unemployment. Aldershot: Ashgate; 2001.

22. Franche RL, Corbière M, Lee H, Breslin FC, Hepburn CG. The Readiness for Return-toWork (RRTW) scale: Development and validation of a self-report staging scale in lost-time claimants with musculoskeletal disorders. Journal of Occupational Rehabilitation. 2007;17(3):450-72. 
23. Frank AW. 'How can they act like that?' Clinicians and patients as characters in each other's stories. The Hastings Center report 2002;32(6):14-22.

24. Franche R-L, Severin CN, Lee H, Hogg-Johnson S, Hepburn CG, Vidmar M, et al. Perceived Justice of Compensation Process for Return-to-Work: Development and Validation of a Scale. Psychological Injury and Law. 2009;2(3):225-37.

25. Roberts-Yates $C$. The concerns and issues of injured workers in relation to claims/injury management and rehabilitation: the need for new operational frameworks. Disability and Rehabilitation. 2003;25(16):898-907.

26. Strunin L, Boden LI. The Workers' Compensation System: Worker Friend of Foe? American Journal of Industrial Medicine. 2004;45(4):338-45.

27. Srivastava P, Hopwood N. A Practical Iterative Framework for Qualitative Data Analysis. International Journal of Qualitative Methods. 2009;8(1):76-84.

28. Brohan E, Henderson C, Wheat K, Malcolm E, Clement S, Barley EA, et al. Systematic review of beliefs, behaviours and influencing factors associated with disclosure of a mental health problem in the workplace. BMC Psychiatry. 2012;12.

29. Hatchard K. Disclosure of mental health. Work. 2008;30(3):311-6.

30. Lemieux P, Durand M-J, Hong QN. Supervisors' Perception of the Factors Influencing the Return to Work of Workers with Common Mental Disorders. Journal of Occupational Rehabilitation. 2011;21(3):293-303.

31. Tjulin Å, MacEachen E, Ekberg K. Exploring Workplace Actors Experiences of the Social Organization of Return-to-Work. Journal of Occupational Rehabilitation. 2010;20(3):311-21.

32. Ekberg K, Wåhlin C, Persson J, Bernfort L, Öberg B. Is mobility in the labor market a solution to sustainable return to work for some sick listed persons? Journal of Occupational Rehabilitation. 2011;21(3):355-65.

33. Lincoln Y, Guba E. Naturalistic inquiry. Newbury Park: Sage; 1985. 
Table 1: Respondents' situation at first interview (2005-2006). Names have been changed for confidentiality.

\begin{tabular}{|lllllll|}
\hline & Gender & Age & Occupation & Diagnosis & $\begin{array}{l}\text { Length of sick } \\
\text { leave }\end{array}$ & $\begin{array}{l}\text { Level of } \\
\text { sick leave }\end{array}$ \\
\hline Lisa & f & 35 & Assistant nurse, elderly care & Depression & 4 months & $100 \%$ \\
\hline Maria & f & 55 & Social worker & Depression & 3 months & $75 \%$ \\
\hline Emma & f & 37 & $\begin{array}{l}\text { Social administration, care for } \\
\text { disabled }\end{array}$ & $\begin{array}{l}\text { Stress, } \\
\text { panic } \\
\text { disorder }\end{array}$ & 1 month & $25 \%$ \\
\hline Lena & f & 45 & Economy assistant, restaurant & $\begin{array}{l}\text { Stress } \\
\text { reaction }\end{array}$ & 6 months & $50 \%$ \\
\hline Alexandra & f & 30 & Nursery school teacher & Burnout & 18 months & $50 \%$ \\
\hline Anna & f & 57 & Interviewer, statistics institute & Depression & 8 months & $50 \%$ \\
\hline John & m & 41 & Social work/school assistant & $\begin{array}{l}\text { Stress, } \\
\text { anxiety } \\
\text { disorder }\end{array}$ & 3 months & $75 \%$ \\
\hline Suzanne & f & 51 & Nurse, elderly care & Burnout & 5 months & $100 \%$ \\
\hline
\end{tabular}

${ }^{a}$ Based on previous level of employment, i.e. a person $50 \%$ sick listed from an $80 \%$ job is in practice sick-listed $40 \%$ of full-time employment.

Table 2: Respondents’ return to work status at second interview (2008-2009), and type of narrative. Names have been changed for confidentiality.

\begin{tabular}{|c|c|c|}
\hline & RTW status & Type of narrative \\
\hline Lisa & Full RTW in previous job. & $\begin{array}{l}\text { Restitution. Unproblematic RTW. Strong work identity. } \\
\text { Supported by manager and colleagues. }\end{array}$ \\
\hline Maria & Full RTW in previous job. & $\begin{array}{l}\text { Restitution. Long history at workplace, strong work identity. } \\
\text { Supported by employer and colleagues. }\end{array}$ \\
\hline Emma & $\begin{array}{l}\text { Full RTW in previous job, } \\
\text { works around } 80-85 \% \text { by } \\
\text { own choice. }\end{array}$ & $\begin{array}{l}\text { Restitution. Thoughts about changing jobs, relatively strong } \\
\text { work identity but sees work as a cause for the illness. }\end{array}$ \\
\hline Lena & Full RTW in previous job. & $\begin{array}{l}\text { Restitution. Thoughts about changing jobs, although not } \\
\text { because of illness. Supported by colleagues, but not } \\
\text { manager. }\end{array}$ \\
\hline Alexandra & $\begin{array}{l}\text { Works } 80 \% \text { in new job, same } \\
\text { profession. }\end{array}$ & $\begin{array}{l}\text { Restitution, focus on continuity. New job but same } \\
\text { profession, strong work identity. }\end{array}$ \\
\hline Anna & Full RTW in previous job. & $\begin{array}{l}\text { Contingent, chaotic and tragic. Little support from } \\
\text { employer. Worried about the future, but focused on } \\
\text { managing the present. }\end{array}$ \\
\hline John & New temporary job. & $\begin{array}{l}\text { Contingent, polyphonic. Previous employer not supportive. } \\
\text { Vague future plans. Scattered work identity. }\end{array}$ \\
\hline Suzanne & Sick-listed 100\%. & $\begin{array}{l}\text { Contingent, chaos and quest. Heroic self-image, perceived } \\
\text { being a victim of unfair treatment from managers, } \\
\text { colleagues and others. Long conflict with employer. }\end{array}$ \\
\hline
\end{tabular}




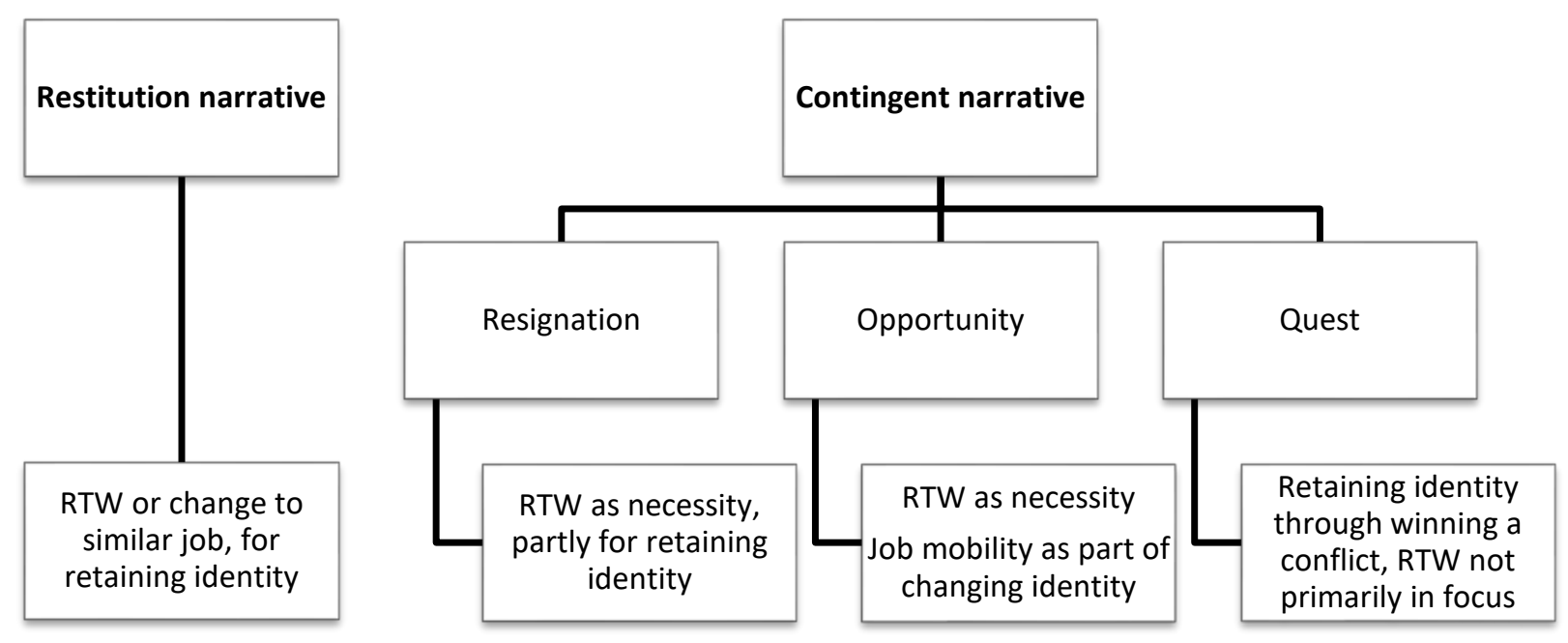

Figure 1: The relation between type of narrative and perceptions of RTW and job mobility in the material 